\title{
Lotte Asveld and Sabine Roeser (eds), The Ethics of Technological Risk
}

\author{
Earthscan, London, 2009, 320 pp. ISBN 978-1-84407-638-3
}

\author{
Neelke Doorn
}

Received: 16 March 2009/Accepted: 18 March 2009/Published online: 2 April 2009

(C) The Author(s) 2009. This article is published with open access at Springerlink.com

Conventional approaches in risk management try to address risks in a 'valueneutral' and 'objective' way. However, recent insights in moral philosophy and the social sciences, notably Science and Technology Studies (STS), have shown that this objectivity is not only illusory, but that this approach can be rendered unfair as well. Risk management is a normative discipline in need of thorough ethical reflection, proponents of a broader conception of risk management argue.

The edited volume The Ethics of Technological Risk presents the state-of-the-art of ethical reflection on technological risks. Based on the presentations at a conference on 'Ethical Aspects of Risks', which took place at Delft University of Technology in June 2006, the editors have compiled over 15 contributions by leading scholars in the field of risk, philosophy, social sciences and psychology. Apart from an introductory and a concluding part the volume consists of four parts, dedicated to Principles and Guidelines, Methodological Considerations, Involving the Public and Instruments for Democratization, respectively. Each part starts with a brief introduction to guide the reader through the chapters and to explicitly mark the cross-relations between the different parts.

The volume starts with an introductory part in which Sven Ove Hansson develops an agenda for the ethics of risks. Hansson discusses four subareas of ethics of risk: the value dependence of risk assessments, ethics as a supplement to standard risk analysis, ethical studies of risk as a means to improve risk analysis and ethical studies of risk as a means to improve moral philosophy. Especially the latter point is refreshing, since it indicates that there is work to do for both moral philosophers and risks analysts alike. Not only should risk analysts become more aware of the ethical aspects of risks, scholars in the field of moral philosophy should also pay more attention to risks in moral theory. At present, moral theories fail to adequately deal with risks and

\footnotetext{
N. Doorn $(\bowtie)$

Department of Technology, Policy and Management, Delft University of Technology,

P. O. Box 5015, 2600 GA Delft, The Netherlands

e-mail: N.Doorn@tudelft.nl
} 
uncertainty since they provide assessments of human behavior in well-determined situations. As such there is something to learn for both risk analysts and moral philosophers. Ten points are identified as needing further research, which are provided with cross-references to the chapters where these issues are already touched upon.

The chapters classified under Principles and Guidelines and Methodological Considerations form the philosophical core of the book. The former part deals with the principles and guidelines that should be adhered to when including ethical considerations in risk management. Starting with a plea for a rich conception of risk by Carl Cranor, the issues of informed consent, liability, and responsibility to others than contemporary human beings are addressed. These chapters, together with the contribution by Hansson, should be compulsory reading for any risk analyst. Douglas MacLean starts the section on Methodological Considerations with a provocative chapter called 'Ethics, Reasons and Risk Analysis'. He convincingly refutes the alleged neutrality of the work done by risks analysts. Due to its inherent ethical and normative concerns, risk management is in fact a branch of ethics, MacLean argues. He criticizes the model based on general preferences, used by economists and risks analysts. By arguing for an active role for risk analysts in informing and advising the public, he provocatively leaves room for a more than descriptive role, i.e., he envisions the risk analysts as influencing individual preferences. The other two contributions to this part on Methodological Considerations are equally important in showing the limits to current approaches in risk management (cost-benefit analysis and welfare judgments).

The introduction to the part on Involving the Public suggests that the inclusion of moral views of the public in risk management is a given. For skeptical readers this suggestion is not evident. However, in the various contributions in this part arguments are given for the inclusion of laypeople's expertise. The part starts with a reprint of 'Risk as analysis and risk as feelings: Some thoughts about affect, reason, risk, and rationality', by Paul Slovic, one of the leading scholars in this field. In the following chapters in this part all authors refer to the work of Slovic and colleagues, but in a critical way, which makes the book a pleasantly heterogeneous reading. The editors have not eschewed to include diverging views. Sabine Roeser criticizes Slovic's use of the Dual Process Theory, in order to arrive at the claim that laypeople's emotions are a source of ethical wisdom about risk. In his contribution 'Risk and Public Imagination', Mark Coeckelbergh criticizes the polarization between expert and public positions by focusing on the role of moral imagination. He argues for a reconsideration of the alleged opposition between feeling and analysis, by introducing the concept of imaginative moral judgment. The last contribution in this section is by Lotte Asveld in which she discusses the way the concerns by the public in the debate on UMTS and GSM mobile phone technology in the Netherlands were set aside by policymakers. She explicitly addresses one of the issues mentioned by Hansson in his introduction, namely the fundamental difference between scientific research and sound risk management especially in terms of the burden of proof (i.e., the choice between avoiding false positives and avoiding false negatives). The inclusion of the public's perspective in this regard may be in the benefit of the whole society, the author argues. Together these contributions do indeed give convincing ground for including laypeople's concerns in risk management. 
Compared to the preceding parts, the contributions in the part on Instruments for Democratization are somewhat disappointing. Though interesting as general attempts to democratize technology, the contributions do not explicitly address technological risks. They have their merits for general technology management, but they do not offer any new insights that are specifically interesting for the field of risk management.

By concluding the volume with a chapter on the relation between systems of risk regulation and self-regulation, the editors have proven foresight. Although the chapter is about technological risks, the conclusions can be applied to others sectors that have to deal with risks as well. In the time that self-regulation by the financial sector has proven not to function adequately, the messages from this chapter should be taken seriously by policymakers in order to improve the process of gaining societally desirable outcomes.

Like other volumes based on conference contributions, the classification of the chapters into six parts is sometimes somewhat artificial. Some chapters would fit under several headings. Especially the distinction between Principles and Guidelines on the one hand and Methodological Considerations on the other is for some chapters somewhat arbitrary. In fact, the part on Methodological Considerations seems mainly to be concerned with methodological objections to current principles and guidelines in risk management.

Apart from the Introduction and Methodological Considerations all parts contain at least one case-based contribution. This prevents the volume from becoming too abstract for the more practically oriented professional. However, the inclusion of these case studies in the theoretical parts sometimes slightly undermines the structure of these particular parts, as a result of which some of the case-based contributions do not appear to full advantage. For example, it is somewhat odd to find Duff Waring's contribution on problems with the bio-ethical principle of clinical equipoise in the theoretical part on principles and guidelines. Although, he does indeed discuss a principle, the text is rather dense and focused on biomedical practice, which makes it difficult to put this text in the context of technological risks. Though well-written, the text is probably too specialized for readers who are interested in a more broad expose on the principles and guidelines for the management of technological risks. A similar remark could be made for the contribution on xenotransplantation and gene-pharming.

This being said, as a whole The Ethics of Technological Risk provides a solidly balanced mix of case-based and more theoretical contributions, which makes it an excellent introduction into the field of the ethics of risks. Both philosophers interested in risks and risks analysts who would like to include moral considerations in their analyses will find the book informative. Much to the editors' credits, provocative chapters and diverging views are included in the volume, which optimally uses the strength of a collection of essays rather than a monograph on the same topic. With the opening chapter by Sven Ove Hansson, the research agenda for the coming years is set.

Open Access This article is distributed under the terms of the Creative Commons Attribution Noncommercial License which permits any noncommercial use, distribution, and reproduction in any medium, provided the original author(s) and source are credited. 